\title{
RESISTANCE PATTERN OF URINARY TRACT INFECTION BACTERIAL ISOLATES TO SELECTED QUINOLONES
}

\author{
*A.R.M Momoh, *M.AC. Odike, * S. Olowo, ${ }^{* *}$ A.A. Momoh, **P.O. Okolo \\ Department of ${ }^{*}$ Pathological Sciences, College of Medicine, A.A.U/IRRUA Specialist \\ Teaching Hospital, IRRUA, Edo State, ${ }^{* *}$ Microbiology, Faculty of Natural Sciences, \\ Ambrose Alli University P.M.B.14, Ekpoma. Edo State.
}

\section{ABSTRACT}

The Quinolones inhibit bacteria by interacting with DNA topoisomerases (gyrases) of which four subunits (two $A$ and $B$ monomers) have been identified thus, inhibiting bacterial DNA gyrase. High level resistance to quinolones can be produced by serial exposure of bacteria to subinhibitory concentration. A Total of 408 suspected UTI and high vagina swab (HVS) samples were examined for bacteria and the isolates obtained tested against the newer quinolones. Prevalence of Bacterial isolates revealed Escherichia coli $110(92 \%)$ as the most isolated organism from urine, while Staphylococcus aureus $31(32 \%)$ was the most isolated species from HVS samples. Bacterial species such as coliforms $55(70 \%)$ and Klebsiella spp 42(84\%), equally had high prevalence rate in urine samples. Pseudomonas aeroginosa 19(66\%) was next to Staphylococcus aureus in terms of prevalence of isolated strains from HVS samples. The resistance pattern observed for these isolates, showed that the strains were least resistant to Ciprofloxacin, followed by Ofloxacin and Perfloxacin, while they were most resistant to Nalidixic acid. There was however no statistical significance $(P<0.001)$ between the use of Ofloxacin and Perfloxacin, however, ANOVA showed a significant difference $(P<0.05)$ between the pattern of Klebsiella spp resistance against Perfloxacin when compared to Proteus vulgaris.
Correspondence:

Dr Momoh Abdul-Razaq mcsionelphilrazzy@yahoo.com

Keywords: Bacterial resistance, Quinolones.

\section{INTRODUCTION}

The introduction of Nalixidic acid in 1962 , began the history of the newer 4quinolone antibacterial agents. The clinical significance of these drugs is based on their broad antibacterial spectrum, unique mechanism of action, good absorption from the gastrointestinal tract, excellent tissue distribution as well as low incidence of adverse reaction ${ }^{1}$.

Recent studies indicate that the mechanism of action of these drugs is the inhibition of DNA topoisomerases (gyrases), thus inhibiting the bacterial DNA synthesis ${ }^{2,3}$. The drugs are bacteriocidal, with a single most bacteriocidal concentration and in greater or lesser concentrations, kill few bacteria. ${ }^{4}$. This Paradoxical effect of decreased killing at higher concentrations is most likely the result of dosedependent inhibition of DNA synthesis ${ }^{5}$.

Antimicrobial Activity: Nalixidic acid has greater antibacterial activity against Gram negative rods than Gram positive bacteria. It is active against most strains of Escherichia coli, Proteus mirabilis, Klebsiella spp and other Coliforms at concentrations easily achieved in the

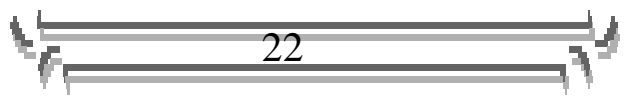


urine i.e. $16 \mathrm{pg} / \mathrm{ml}$ or lower ${ }^{6}$ Gram positive organisms like Staphylococcus aureus, Streptococcus pneumonia and Streptococcus faecalis are resistant to Nalixidic acid. ${ }^{7}$

Norfloxacin which is 100 times more active compared to Nalixidic acid, has a spectrum that includes entrococci, Staphylococci and Pseudomonas species. ${ }^{8}$ It is active against most Gram positive and Gram negative bacteria implicated in UTI at concentrations easily attained in the urine. Norfloxacin is active against Haemophilus influenza, Neisseria gonorrhoea, regardless of beta-lactamase activity. However, it is less active against methicillinresistant strains of Staphylococcus aureus. $^{9,10}$.

Ciprofloxacin is said to be more potent than Norfloxacin, and is also active against most Gram positive and Gram negative infectious bacteria at concentrations easily attained in most tissues and body fluids. ${ }^{11}$. Ciprofloxacin has excellent activity against Chlamydia trachomatis and genital Mycoplasma, inhibiting $90 \%$ of isolates at $1 \mathrm{ug} / \mathrm{ml}$ concentrations. $12,13,14$. However, reduced susceptibility of these organisms to Ciprofloxacin occurs following serial exposure of the organisms to subinhibitory drug concentrations, this invariably may lead to cross resistance to other quinolones by the organisms ${ }^{14}$.

Though, exact mechanism of bacterial resistance to the quinolones is unknown, it may occur when serine in position 83 of subunit $A$ is replaced by trypophan ${ }^{15}$. Or when inhibition of topoisomerase $1 \mathrm{~V}$ interfere with replicated chromosomal DNA ${ }^{16}$. Finally, it could be due to a mutation in the gene coding for DNA gyrase or a mutation that alters the bacteria's outer-membrane porins ${ }^{17}$.
In this work, we identified and assessed the prevalence of bacteria in UTI as well as determined the current trend in the resistance pattern of the bacteria isolates to the selected quinolones.

\section{MATERIALS AND METHODS}

Specimen:

A total of 408 clinical specimens comprising of $305(75.25 \%)$ urine samples and $103(25.75 \%)$ of high vaginal swab (HVS) samples. All specimen were transported to the laboratory and were processed within 2hours of collection.

\section{Isolation and identification:}

The specimens were innoculated onto Nutrient agar, Blood agar and MacConkey agar plates by streaking. Inoculated plates were then incubated aerobically at $37^{\circ} \mathrm{C}$ for 24 hours. After 24 hours of incubation, discrete colonies were picked up and Gram stained and further subculturing was done to obtain pure cultures and biochemical tests carried out.

\section{Antimicrobial Susceptibility Testing}

This was done by the disc diffusion method. All isolates were subjected to testing using Nalidixic acid, Perfloxacin, Ciprofloxacin and Ofloxacin.

Staphylococcus aureus, Oxford stain NCTC 6751 was used as control for Gram-positive organisms while Escherichia coli NCTC 10418 was used as control for Gram negative organisms.

The results of the susceptibility test were interpreted as sensitive, intermediate or resistant, using the criteria below:

A zone's radius equal to or not more than $3 \mathrm{~mm}$ smaller than the control was reported as sensitive.

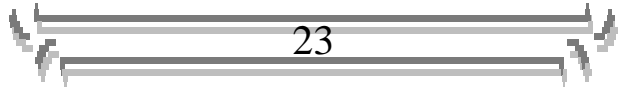


A zone's radius more than $3 \mathrm{~mm}$ smaller than the control but not less than $3 \mathrm{~mm}$ was reported as intermediate or moderate.

A zone's radius of $2 \mathrm{~mm}$ or less (i.e., no zone of inhibition) was reported as resistant.

RESULTS
A total of 408 suspected UTI and vaginitis samples were analysed during this study. Of these samples $305(75.25 \%)$ were urine samples and 103(25.75\%) were high vagina swab (HVS) samples. Males contributed $156(51.51 \%)$ of the urine samples while a total of 103(100 ${ }^{*}$ L) HVS samples were collected from females 18years and above.

Table 1: Prevalence of Bacterial Strains Obtained From Urine and HVS Samples

\begin{tabular}{|c|c|c|}
\hline \multirow{2}{*}{ Bacterial Strains } & \multicolumn{2}{|c|}{ No of Isolates obtained from } \\
\hline & Urine Samples & HVS Samples \\
\hline Escherichia coli & $110(92 \%)$ & $9(8 \%)$ \\
\hline Staphylococcus aureus & $67(68 \%)$ & $31(32 \%)$ \\
\hline Coliforms & $55(70 \%)$ & $23(30 \%)$ \\
\hline Klebsiella spp & $42(84 \%)$ & $89(16 \%)$ \\
\hline Proteus mirabilis & $18(60 \%)$ & $21(40 \%)$ \\
\hline Pseudomonas aeroginosa & $10(34 \%)$ & $19(66 \%)$ \\
\hline Proteus vulgaris & $3(100 \%)$ & $0(0 \%)$ \\
\hline Total & $305(75.25 \%)$ & $103(25.75 \%)$ \\
\hline
\end{tabular}

Table 1.shows the prevalence of bacterial strains obtained from both urine and HVS samples. Escherichia coli has the highest prevalence among the bacterial isolates, with 119 samples. Of this total, $110(92 \%)$ were isolated from urine and $9(8 \%)$ was isolated from
HVS samples. Staphylococcus aureus were isolated in 98 samples, 67(68\%) from urine samples and $31(32 \%)$ from HVS samples. Klebsiella species were isolated were isolated from 50 samples 42 from urine sample (84\%) and 8 from HVS samples (16\%).

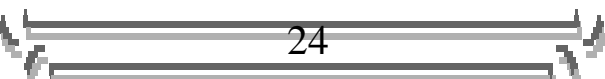


Table 2: The Susceptibility Pattern of Bacterial Isolates and the Percentage (\%) Resistance to the Selected Quinolones

\begin{tabular}{lcllll}
\hline \multirow{2}{*}{ Bacterial Strains } & \multicolumn{5}{c}{ № (\%) Resistance to the Quinolone } \\
\cline { 2 - 6 } & $\mathbf{n}$ & \multicolumn{1}{c}{ PER } & \multicolumn{1}{c}{ CRP } & \multicolumn{1}{c}{ OFX } & \multicolumn{1}{c}{ NA } \\
\hline Escherichia coli & 119 & $30(252 \%)$ & $37(31.1 \%)$ & $28(23.5 \%)$ & $45(37.8 \%)$ \\
Staphylococcus aureus & 98 & $16(16.3 \%)$ & $8(8.2 \%)$ & $8(8.2 \%)$ & $37(37.6 \%)$ \\
Coliforms & 78 & $18(22.8 \%)$ & $6(7.6 \%)$ & $18(22.8 \%)$ & $45(60.0 \%)$ \\
Klebsiella spp & 50 & $10(20.0 \%)$ & $10(20.0 \%)$ & $8(16.0 \%)$ & $22(44.0 \%)$ \\
Proteus mirabilis & 30 & $5(16.7 \%)$ & $2(6.7 \%)$ & $7(23.3 \%)$ & $5(16.7 \%)$ \\
Pseudomonas aeroginosa & 29 & $6(20.7 \%)$ & $0(0.0 \%)$ & $9(31.0 \%)$ & $9(31.0 \%)$ \\
Proteus vulgaris & 3 & $2(66.6 \%)$ & $0(0.0 \%)$ & $0(0.0 \%)$ & $1(33.3 \%)$ \\
\hline
\end{tabular}

Key:

$\mathrm{n}=$ number of strains tested

$\begin{array}{lll}\text { PEF } & = & \text { Perfloxacin } \\ \text { CRP } & = & \text { Ciprofloxacin } \\ \text { OFX } & = & \text { Ofloxacin } \\ \text { NA } & = & \text { Nalixidic acid }\end{array}$

Table 2 shows the selected quinolones used and the isolates susceptibility pattern. Escherichia coli had 30 strains resistant to perfloxacin, 37 were resistant to Ciprofloxacin, 28 and 45 isolates were resistant to Ofloxacin and Nalixidic acid.
Nalixidic acid unarguably is the least sensitive of the selected quinolones, virtually all other bacterial isolates showed increased resistance to Nalidixic acid than the other selected quinolones.

Table 3: In-vitro Antimicrobial Activity of the Selected Test Quinolones against Isolated Bacterial Species.

\begin{tabular}{llccc}
\hline \multirow{2}{*}{ Bacterial Strains } & \multicolumn{4}{c}{ Mic $(\mu \mathrm{g} / \mathrm{ml})$} \\
\cline { 2 - 5 } & $\mathbf{n}$ & PER & CRP \\
\cline { 2 - 5 } Escherichia coli & 0.039 & 0.250 & 0.125 & 5.000 \\
Staphylococcus aureus & 0.250 & 0.250 & 0.039 & 5.00 \\
Coliforms & 0.063 & 0.500 & 0.500 & 5.000 \\
Klebsiella spp & 0.250 & 0.500 & 0.250 & 10.000 \\
Proteus mirabilis & 0.250 & 0.500 & 0.250 & 10.000 \\
Pseudomonas aeroginosa & 0.500 & 5.000 & 5.000 & 10.000 \\
Proteus vulgaris & 0.063 & 0.250 & 0.250 & 0.500 \\
\hline
\end{tabular}

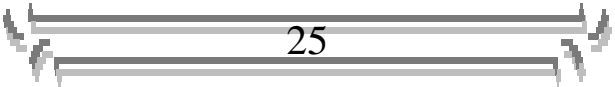


In table 3, the minimum inhibitory concentration (MIC) in $\mu \mathrm{g} / \mathrm{ml}$ of Escherichia coli to Nalixidic acid was observed to be $5.0 \mu \mathrm{g} / \mathrm{ml}, 0.059 \mu \mathrm{g} / \mathrm{ml}$ to Perfloxacin, $0.250 \mu \mathrm{g} / \mathrm{ml}$ and $0.125 \mu \mathrm{g} / \mathrm{ml}$ to Ciprofloxacin and Ofloxacin respectively.

Ofloxacin was observed to be a more potent for Staphylococcus aureus with the organisms having a MIC of 0.039 to Ofloxacin, and $0.250 \mu \mathrm{gml}$ to both Perfloxacin and Ciprofloxacin respectively and $5.00 \mu \mathrm{g} / \mathrm{ml}$ to Nalixidic acid.

\section{DISCUSSION}

The selected quinolones proved to be of chemotherapeutic value against the 408 samples analysed in the cause of this work. Some strains however were resistant. This work agrees with other similar works, especially with respect the incidence rates of Escherichia coli. Escherichia coli had earlier been reported as being the most prevalent organism implicated in $\mathrm{UTI}^{18}$. Escherichia coli was observed in this work to have $29.17 \%$ prevalent rate of $24.02 \%$. These prevalent rates makes Escherichia coli and Staphylococcus aureus the two most implicated organism in UTI, as well as the most prevalent Gram-negative and Grampositive organisms respectively.

Nalixidic acid was seen to be the least potent of the selected quinolones. However, there is no statistical significance $(p<0.001)$ between the use of Ofloxacin and Perfloxacin in the treatment of the isolated strains.

The pattern of Klebsiella spp resistance against Perfloxacin when compared to Proteus vulgaris was significant. In the same manner, the analysis of variance between the pattern of resistance against Perfloxacin shown by Pseudomonas aeruginosa compared to Proteus vulgaris was significant.

\section{CONCLUSION}

This study has been able to show that there is no real difference in therapeutic valve between the selected quinolones, safe for Nalixidic acid, which seen to have a wide range of resistance among the isolated organisms.

However, it is a first generation quinolone, compared to the other three which are second generation drugs.

The study has also shown that Gram-negative organisms, especially Escherichia coli are predominantly responsible for UTI, and Staphylococcus aureus is the most prevalent Grampositive organisms implicated in UTI, although other Gram-positive organisms like Streptococcus species could be implicated.

It is hoped that findings from this study would be of help in:

Monitoring antimicrobial susceptibility, to ensure informed usage of antibiotics and usefulness of these drugs for longer period of time.

Assist in effective management of UTI cases.

Give a guide-line in choice of drug when certain related organisms are implicated in a UTI.

\section{REFERENCES}

1. Klepser MR (1999): Overview of the in vitro activity of the newer fluoroquinolones. Journal of infections Disease pharmacotherapy 4(2):1-12.

2. Jawetz E (1998): Antimicrobial Chemotherapy In: Brooks GF, Butel JS, Morse SA, eds. Medical Microbiology. $21^{\text {st }}$ ed. Stamfordconnecticut: Appleton and Lange, Pp 173-175.

3. Rybak MJ (1999): Mechanism of fluoroquinolone resistance and the role of topoisomerase activity. Journal of infectious Disease Pharmacotherapy 4(2): 13-20.

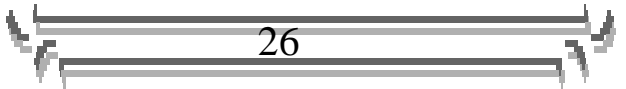


4. Crumplin GC (1987): Plasmidmediated resistance to Nalixidic acid and new 4-quinolones, Lancet (8): 854-859.

5. Smith JT, Lewin CS (1988): Chemistry and mechanisms of action of the quinolone antibacterials. In Andriole VT (ed): The Quinolones. London, Academic Press, pp 23- 81.

6. Barlow AM (1963): Nalixidic acid in infections of urinary tract. British Medical Journal (2): 1308-1311.

7. Lesher GY, Froclich EJ, Gruett MD (1962): 1,8-napthyridine derivatives. A new class of chemothera peutic agents. Journal of Medical Pharmacology Chemotherapy 2(5): 1063- 1069.

8. Ito A. Hiria K, Inoue M, (1980): In vitro antibacterial activity of Am 75 , a new nalidixic acid analog. Antimicrobial Agents Chemotherapy (17): 103-105.

9. Neu HC, Labthavikul P (1982): Invitro activity of norfloxacin, a quinolone carboxylic acid, compared with that of $\beta$-lactams, aminoglycosides, and trimetoprim. Antimicrobial Agents Chemotherapy 911): 369374.

10. Corrado ML, Chervbin CE, Shulman M (1989): The comparative activity of norfloxacin with other antimicrobial agents against Gram-positive and Gram-negative bacteria Journal of Antimicrobial Chemotherapy (11): 369-372.

11. Nicolau DP (1999): Establishing the clinical role of the new fluroquinolones. Journal of Infectious Disease Pharmacotherapy 4(2): 35-44.
12. Hessen FWA, Myutjens HL (1984): In-vitro activities of ciprofloxacin, norfloxacin, pipemidic acid, cinoxacin and nalixidic acid against Chlamydia trachomatis. Antimicrobial Agents Chemotherapy (24):123-129).

13. Wolfson JS, Hopper DC (1985): The fluoroquinolones: structure, mechanism of action and resistance and resistance and spectra of activity in-vitro. Antimicrobial Agents Chemotherapy (28): 581-586.

14. Norris S, Mandell CL (1988): The Quinolones: History and Overview. In Andriole VT (ed): The Qui nolones. London. Academics Press, pp 290-314.

15. Hirai K, Sazue S, Irikura T. (1987): Mutations producing resistance to norfloxacin in Pseudomonas aeruginosa. Antimicrobial Agents Chemotherapy (31): 582-585.

16.Pan XS, Fisher M. (1996): Cloning and characteristics of the par $\mathrm{C}$ and par genes of Streptococus pneumoniae encoding DNA topoisomerase IV: Role in fluoroquinolone resistance. Journal of Bacteriology (178): 40604062.

17. Chapman JS, Bertasso A, Georgopapadakuo N H (1989): Fleroxacin resistance in Escherichia coli Antimicrobial Agents Chemotherapy (33): 239-244.

18. Davidson S (2006): Disease due to infection In: Nicholas B, Nicki RC, Brain RW, eds. Principles and practice of Medicine $20^{\text {th }}$ ed. New York: Churchill Livingstone, pp 467468.

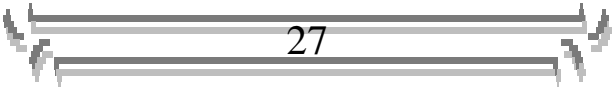

